\title{
Environmental communication in and about China: A review of the Chinese-language literature
}

This is the final version submitted before publication in Chinese Journal of Communication.

Corresponding author: Jingrong Tong, Department of Social Sciences, Media and Communications, Brunel University London, The United Kingdom.

Email: jingrong.tong@brunel.ac.uk

\section{Abstract}

This article offers a review of the Chinese-language literature on environmental communication in mainland China. In particular, it discusses the main features, promises, and limitations of the relevant literature. All academic papers matching particular keywords for environmental communication in seven top-ranking Chinese-language media and communication journals (four in Mainland China, one in Hong Kong, and two in Taiwan) were collected and analyzed quantitatively. The first section of the article presents the findings of the quantitative analysis based on several aspects, including the journals' main interests, distribution of publications over time, types of topics, research methods, leading authors in the field, their choices of research methods and topics, and the inclusion of English-language literature. The article turns to qualitatively examine the wider available Chinese-language literature on environmental communication. It then evaluates the current status of and challenges to Chinese-language research in this field and suggests some directions for future research.

Keywords: Environmental communication research, Chinese-language literature, review 


\section{Introduction}

Environmental communication concerns not only media representation and public perceptions of nature and the environment but also the participation of social actors in environment-related decision-making and how that participation influences business, political, and civic lives (Cox, 2013). Following suggestions by Hansen and Cox (2015a), this article focuses on (news and new) mediamediated communication on or about the environment and environmental issues largely because of the importance of media-mediated communication in our public lives (Hansen \& Cox, 2015a).

In the English-speaking world, environmental communication research can be traced back to the 1970s, and it has been established as an institutionalized academic field for several decades (KatzKimchi \& Goodwin, 2015; Hansen \& Cox, 2015a). Studies of environmental communication are often interdisciplinary and encompass a wide spectrum of topics, including environmental rhetoric, discourse and representation, public understanding and perceptions of nature and the environment, environmental campaigns and participation, environmental journalism, science, risk and crisis communication, and so on (Cox, 2013; Hansen \& Cox, 2015b; Cox \& Depoe, 2015; Bødker \& Neverla, 2012). In recent years, scholars have begun to examine environmental communication on the Internet or social media, which has gone beyond the scope of the mainstream mass media and has taken into account the contribution of the activities of non-media actors to environmental communication (Autry \& Kell, 2012; Alexander, 2013; Merry, 2014; Bortree, 2012).

Because it is a burgeoning field of research in China, environmental communication research has a relatively short history of less than two decades. One major contribution that publications in the Chinese language can make is associated with the fact that most international journals are in English, which is likely to disadvantage Chinese scholars who are not proficient in the English language. Hence, publishing in Chinese allows them to contribute to the construction of knowledge in the field without the challenge of a language barrier. For some scholars who are able to read the English language literature, writing Chinese-language articles allows them to bridge the literature in both 
languages. This is a valuable contribution to ensuring academic diversity and pluralism in the field of environmental communication at the international level. Because environmental problems and issues have been in the spotlight in China since the 1980s, it is important to understand what topics have been studied, what has been discovered about China's environmental communication, and, equally, what has been left unresearched. This knowledge not only offers us an understanding of environmental communication in China but also helps inform public debates on related issues in order to facilitate environmental communication and influence environment-related policy-making. In China, environmental communication is subject to the political control of the Chinese government. Chinese news media that have already been commercialized are still state-owned and expected to function as ideological state apparatuses. Either environmental communication or environmental communication research may embody such an authoritarian feature. Nevertheless, only a few systematic reviews have examined environmental communication research in and about China. To fill this gap, this essay will offer a review of Chinese-language literature on environmental communication in mainland China. In so doing, we will be able to map out where there has been progress and then proceed to delineate major dimensions, challenges, and directions for future research.

\section{Chinese-language studies of environmental communication in and about China}

In order to sketch out the field, following the analytical model proposed in the study of Wang and Lee (2014), we first conducted a small quantitative content analysis exercise, looking at related publications to examine their main features, such as the over-time distribution of publications, types of topics, research methods, the varied interests of journals in publishing articles on environmental communication, leading authors in the field and their choices of research methods and topics as well as the inclusion of English literature. The aim of this exercise was to give us a quick sense of the field.

For this exercise, we selected seven Chinese-language media and communication journals: the Journal of International Communication (guoji xinwen jie), Modern Communication (xiandai 
chuanbo), Journalism Bimonthly (xinwen daxue), Journalism and Communication (xinwen yu chuanbo) (published in mainland China), Communication and Society (chuanbo yu shehui, based in Hong Kong), Mass Communication Research (xinwenxue yanjiu) and the Chinese Journal of Communication Research (zhonghua chuanbo xuekan) (the last two published in Taiwan) for further analysis. They were selected because they are the most important and prestigious Chinese-language media and communication journals in mainland China, Hong Kong and Taiwan (Wang \& Lee, 2014). Although these journals should be able to offer us an understanding of the highest quality scholarly work in this field (Wang \& Lee, 2014), because of its selective nature, this small scale content analysis is used as a point of departure for the discussion in the paper.

After a few tests ${ }^{1}$, the following specified nine keywords covering environmental communication in the Chinese context were used to search in the Chinese Journal Full-text Database (zhongguo qikan quanwen shujuku) and on the websites of these journals (if they have any): "environment (huanjing)", "ecology (shengtai)", "risk (fengxian)", "environmental protection (huanbao)", "green (Ivse)", "climate (qihou)", "nature (ziran)", "haze (wumai)", and "PM2.5". All papers matching one of the keywords were collected, followed by a close examination of these papers, to remove those which proved irrelevant. For example, despite including one or several of the specified keywords, some articles actually talked about the media environment and therefore were excluded. Several other articles were filtered out because they addressed environmental issues that are not about China. In addition, the Chinese Journal of Communication Research (Taiwan) has no publications on environmental communication in mainland China at all. Therefore, we focused on the six Chineselanguage journals that have published relevant articles. Five main coding variables were developed for the content analysis, including types of topics, methods, years, authors and inclusion of English literature, with the purpose of understanding the basic nature of Chinese-language literature on the environment and environmental issues, as published by the seven academic journals. 
The findings of this small exercise have five implications. Firstly, this is a small developing area with literature in its infancy. In total the final sample for analysis includes 65 articles on China's environmental communication for all available years. By any standards, 65 articles published in seven top media and communication journals for all these years is not a great number. From Figure 1, we can see the first publication on related topic appeared in Modern Communication in 2001. The number of publications started to increase from 2009 and reached a peak in 2013 with a clear focus on topics related to media representations or discourses of 'environmental events, issues and agendas' as well as 'NGOs, environmental protests, conflicts and movements'. There was a small decrease from 2013 to 2014 but the number of publications remained stable in 2014 and 2015 . Figure 2 shows Modern Communication has the strongest interest in publishing Chinese environmental communication studies, while the interest of Hong Kong's Communication and Society in related topics is slightly higher than that of its Taiwan counterpart Mass Communication Research.

[Figure 1 is about here]

[Figure 2 is about here]

Secondly, in terms of the quantity of the publications, no authors have dominated the discussions or are leading the research in this field. Both Fanxu Zeng and Hongfeng Qiu, who are top two most productive first authors, have published four articles as the first author and have employed empirical research methods such as content analysis, interviews and observation in their studies. While Fanxu Zeng has a preference for content analysis and case studies, Hongfeng Qiu shows diverse interests and has combined the use of content analysis, interviews and observation in his research.

Thirdly, the Chinese-language literature has started to cite the English-language literature over recent years (see Figure 4). About 33 per cent of the articles did not cite any English-language literature. Starting from 2009, English-language literature has been increasingly cited in the Chinese- 
language literature (see Figure 4). It is evident that over the last three years, from 2013-2015, there has been a sharp rise in citing English-language literature on risk communication, social theories and methodologies. It is a good sign, suggesting the start of establishing a kind of connection between the Chinese-language and English-language literature. English-language literature on risk communication and social theories such as theories of social movements and conflicts are most cited, taking 18.4 per cent and 12.6 per cent respectively. In addition, articles on 'environmental movements, events and issues' have consulted English-language literature the most, followed closely by articles on 'NGOs, environment protests, conflicts and movements'. The implication of this point is that scholars who are interested in such topics are those who are willing and able to read English-language literature and their interest is one driving force behind the development of this burgeoning field.

[Table 1 is about here]

[Figure 3 is about here]

[Figure 4 is about here]

[Figure 5 is about here]

Fourthly, most academic attention has been paid to the media representation of environmental events such as protests and conflicts. The topics of the publications can be classified into eight categories. Clearly the category of 'environmental events, issues and agendas', such as pollution and climate change takes the biggest proportion of 39.1 per cent, and that of 'NGOs, environmental protests, conflicts and movements' is in second place. This pattern matches that of citing Englishlanguage literature discussed above. Academic interest in the topic of 'environmental events, issues and agendas' started emerging from 2006, while scholars began to research the topics related to 'NGOs, environmental protests, conflicts and movements' from 2008. The studies falling within both categories have a focus on analysing media frames and discourses of these events. Surprisingly little 
attention has been given to examining the public perception of the environment and media representation, the practices of environmental journalism and reporting as well as the practices and communication strategies of environmental protestors, governments, officials, big businesses, corporations and NGOs that may influence the production of environmental messages.

Finally, in terms of the methodologies used in these studies, nearly half of these publications (44.6\%) are not primary research articles, in the sense that they have not used any practical research methods to collect and analyse empirical data. The first publication to adopt an empirical research method was published by Communication and Society in Hong Kong in 2009. Content analysis was used in this article to analyse media framing of environmental events. Compared to other types of empirical research methods such as interviews, surveys and observation, content analysis is the most popular research method, which some 34 per cent of the publications have used. Only a very tiny proportion of studies have collected data through interviews, questionnaires or observations.

\section{The known and unknown knowledge}

The quantitative content analysis of selected samples presented above gives us an initial idea of the contour of environmental communication research in and about China. Now we shall proceed to probe further, and in more detail, into what the field tells us about China's environmental communication and what remains unknown. To achieve this purpose, we will have to look at the wider available Chinese-language literature, such as books, research theses and publications in other journals, rather than merely being restricted to the selected samples for the quantitative analysis. Google Scholar and the CNKI website (http://gb.oversea.cnki.net/kns55/) were used to search for relevant articles, books and theses. The above nine keywords were used in the searches. Given that the focus of this article is on media-mediated environmental communication, academic disciplines including 'theories and methods in social science', 'sociology and statistics' and 'journalism and media' were included in searches on the CNKI website ${ }^{2}$. In addition, we will take Hansen's suggestions for environmental communication research (Hansen, 2011; Hansen, 2015) and 
particularly examine environmental communication research in the three conventional domains: production, content and audience.

\section{Production}

A closer look into the literature reveals that current Chinese-language environmental communication research has produced little knowledge in relation to the production of environmental information and the underlying influencing factors. This matches the findings of the quantitative analysis. There is a severe lack of understanding of how environmental journalists report on nature and the environment and what factors are influencing and even interfering with their practices. Only a very little research has been done on relevant topics. For example, the Masters' dissertation by Pei (Pei, 2009) examines the factors affecting environmental news production in a party organ. Pei's study confirms the dominance of official news sources, which suggests environmental news in the party outlet continues to interpret environmental regulations and promote governmental achievements.

The current Chinese-language literature has not presented any sufficient and systematic evidence about the detailed scenarios in which environmental journalists do their jobs, such as the relationship between environmental journalists and news sources, the role played by news values and organisational determinants, and news management of campaigners, governments, influential commercial corporations and other political and commercial actors, which are, by contrast, exactly central to the focus of the English-language literature on environmental communication (Hansen, 2015). The knowledge of these aspects however, can give us an in-depth, reflexive and critical understanding of the power relations in environmental communication. In particular, the available knowledge about commercial and political influences on environmental reporting is extremely limited despite its importance in the context of China. This is partly because most of the time environmental-related news reports are intrinsically negative, and this may not be welcomed ( even covered up) by governments and businesses (Tilt \& Xiao, 2010; Fong, 2008). The tradition of media 
control in China means many kinds of intervention into journalistic practices and such intervention may even take the form of commercial censorship on some occasions (Tong \& Sparks, 2009). This in turn suggests researching environmental journalism and reporting may be a sensitive topic for researchers in China.

Within this context, therefore, the study by Huang and Zeng (Huang \& Zeng, 2010) is considered particularly valuable because they have examined how protestors in four environmental protests interacted with local media and influenced media and the public agenda with their claims. . Their methodological and analytical approach is rarely seen in other environmental communication studies, though it would have told a fuller story if it had also revealed how the reports on these protests were produced and if the comprehensive and even entangled relationship between environmental protests and local media (and that between protestors and journalists) had also been analysed.

In contrast to the paucity of environmental news production studies, examining the general development of environmental reporting is a popular topic. This is especially true of those articles published by journals whose main area of interest is the practical aspect of journalism. These journals range from China Journalists (zhongguo jizhe), News and Writing (xinwen yu xiezuo), Journalism Practices (xinwen shijian) to Journalism Frontline (xinwen zhanxian). These articles focus on studying the patterns of and problems with environmental reporting. Quite a number of postgraduate research theses at both the Masters and $\mathrm{PhD}$ levels have also addressed related topics. These publications have contributed to an adequate construction of knowledge of what environmental news is about as well as the development, genres and topics of environmental news and reporting in China. According to these studies (such as Li, 2007a; Chen, 2012; Ji, 2007; Zhao \& Zhou, 2012; Liang \& Deng, 2006), environmental reporting appeared as a genre of reporting in the 1980s when the Chinese government started to highlight the importance of environmental protection alongside that of economic development. In spite of the changes in topics over time, this 
genre of news mainly concentrates on environmental regulation implementation, governmental achievements, environmental pollution, deterioration and problems, as well as the achievements of selected environmental protection NGOs and activists. Environmental reporting, according to these authors, should be helping resolve environmental problems and improve environmental protection and governance. These topics and arguments suggest a pro-government stance these authors have been taking on, which, of course, may be encouraged by the government.

This pro-government stance is also reflected in seeing environmental reporting as part of government propaganda work (xuanchuan gongzuo). Academic publications in the late 1990s and the early $21^{\text {st }}$ century (such as Li \& He, 2000) and some more recent publications (such as Li, 2007b) even treat environmental reports as an extension of the Party's propaganda work and the purpose of these articles is to offer suggestions on how to report on the environment correctly in political terms and how to facilitate the government's work. Having that said though, we should recognize since the turn of the $21^{\text {st }}$ century there have been changes in academic thinking about the role of environmental reporting. This new trend can be seen in a small number of publications that advocate the need to shift the role of environmental journalists from being propagandists to professional journalists (such as Huang \& Lei, 2013; Zhang, 2007).

\section{Content}

The content domain of environmental communication research is the most fruitful. Scholars have done a relatively decent job in analysing the media representations and discourses of environmental events, about which we therefore have a good body of knowledge. Especially in the most recent decade, a number of scholars have analysed and delineated the patterns and meanings in the media content of environmental events such as pollution incidents or environment-related protests in traditional and social media. Almost all of these studies have used one or more types of content analysis to analyse media texts (Liu, 2014), though very few of them have examined images. 
In this domain of environmental communication research, we can also detect the pro-government stance of some scholars (such as Xu \& Yu, 2010; Liu, 2010; Qu \& Lu, 2010; Huang \& Ding, 2010), who link the coverage of China's environmental problems by Western media with the national image of China or of the Chinese government. They conclude that Western news media tend to cover China in a negative way and contend that the influence of national ideologies is identifiable in the foreign coverage of Western news media. Concurrently however, there are scholarly works taking a more critical stance toward environmental problems in China. From their studies (such as Huang \& Liu, 2014; Shi, Zi, Feng, \& Fan, 2010), we understand pollution, ecology deterioration, and desertification are among the main types of environmental problems constructed in media coverage, and encouragingly prominence has been given to environmental protection programmes and campaigns such as Lucky Earth Village (xinyun diqiuchun) and Keke Xili Protection (Wang, 2005). NGOs, and in some cases even government-organised NGOs (GONGO), have also been found to be playing an increasingly important role in pushing forward environmental movements and campaigns. These NGOs, such as Green Peace, Friend of Nature (ziran zhiyou) and the China Forum of Environmental Journalists (zhongguo xinwen gongzuozhe xiehui) actively set agendas and frames in media coverage as demonstrated in the case of $\mathrm{APP}^{3}$ destroying primeval forests in Yunnan and in the case of laying an anti-leakage plastic film at the bottom of the Yuan-Ming lake (Zeng, 2009a).

The relationship between the environment and society has become a major topic of environmental communication research. A number of studies (such as Liu, 2014; Bai, 2014; Zeng, 2009b; Zeng, 2009a; Sun, 2009; Huang \& Zeng, 2010) have examined environmental events and issues in connection with social dynamics and power relations, in particular paying extensive attention to environmental protests, movements and public participation. These studies not only convey information about how the environment and environmental events have been represented but also place an emphasis on the role of mass media and factors that have an impact on such a role. Bai Hongyi, for example, has completed an interesting study examining the news frames, sources and attitudes in the media coverage of three environment-related "not-in-my-backyard" conflicts in 
2012 (Bai, 2014). His study reveals several prominent and anti-hegemonic journalistic paradigms in the coverage of these events by the six media outlets analysed. The fact that these media outlets picked the side of the protestors over the authorities is unexpected and prompts us to rethink the news values and roles of contemporary mainstream news media in authoritarian China. However, the content analysis by Qing Wang points out that the state still has the upper hand in manipulating the discourse about smog, functioning as dominant official news sources for the People.net (renmin wang) and blaming enterprises and the public for the proliferation of atmospheric pollution (Wang, 2014). Yin has examined the way news media represent an environmental event and noted how that relates to their geographical proximity to the locality where the event happens and the nature of these news media, whether a party organ or a commercial newspaper (Yin, 2010).

In addition, over recent years, there has been a trend to a number of studies using social theories which originated in Western contexts, such as Beck's idea of "risk society" and related concepts (Beck, 1992) and have touched on analysing the discourses of environmental risks. Coherent with what was revealed in the quantitative content analysis, research on environmental events, protests and issues are more inclined to use theories developed in Western societies. However, such references to the English-language literature cannot be seen as a true dialogue between the literature in the two languages. This is because mostly these studies merely bring in such concepts and apply them in the Chinese context without careful reflection and without developing critical thinking in related issues. For example, the concepts of 'risk communication' and 'risk perception' are only briefly introduced at the start of an article examining the news coverage of the 2014 Three Gorges project event. Although interesting, the article discusses neither the applicability of the concepts nor how the Chinese case contributes to our understanding of them ( $\mathrm{Li}$, Yang, \& Yang, 2015). These studies on environmental risks often examine the implications of environmental events or protests to gain some understanding of risk communication or how to better handle risk communication so as to reduce risks concerned. 
While most of time content analysis is used, these studies occasionally combine content analysis with other research methods of data collection such as interviews with social actors involved. Some studies (such as Li, et al., 2015; Zeng, Dai, \& Wang, 2015; Zeng, Dai, \& Zheng, 2013) analyse the coverage either in traditional media or on the Internet (or both), and some of them compare the two versions of the coverage by traditional and online media to interpret the roles played by each medium. The study by Zeng and his collaborators is a good example of this; it examines not only media content but also the effects of media content (Zeng, et al., 2015). Their work allows us to understand how environmental risks posed by nuclear plants were amplified in the public's perception, which consequently led to public protests against the construction of the Rongchengshidaowan Nuclear Plant and the Rushanhongshiding Nuclear Plant (both in Shandong Province). They analysed traditional and social media coverage of nuclear electricity and nuclear plants and interviewed a number of social media users and protestors. Their study attributes the amplified perception of nuclear plants and the protests that subsequently took place to a number of reasons, including local governments' inability to provide transparent information about the two projects, the dysfunctional nature of the NGOs, public outrage, the stigmatisation of the projects, especially on social media and the "opposing reading" by the public. Social media played a crucial role in mobilising the public, becoming the main arena for experts and social media opinion leaders to control the discourse of risk associated with nuclear electricity.

The increase in interest in analysing media content about these particular topics is down to a number of influences. The rise of environmental reporting itself provides a multiplicity of opportunities for scholars to explore the features of environmental communication in China. Given that environmental events have become a major source of social tension over recent years, related topics are of importance to academic researchers. Increasingly intense environmental conflicts and protests makes the question of how news media handle these conflicts and protests vital. It is crucial to generate and gain knowledge of media representation of environmental events as well as of the news media's portrayal of, and attitudes towards, different social actors involved in the process. 
Despite an upsurge in content analysis-based research, few Chinese-language academic studies so far have looked into the relationship between humanity and nature as represented in media content. In other words, current research mostly ignores topics related to nature and the environment itself. How the environment and nature is portrayed in media coverage has been largely neglected in academic research, though it should be of much interest and importance to academics. The quite small number of articles that have touched on related topics mainly fall within the domains of literary critique and aesthetics. A good example of this genre is the essay by Tian that discusses the shift in ecology aesthetics from 'conquering nature' to 'being close to nature' as embodied in Chinese documentaries, though no empirical content analysis methods have been employed (Tian, 2009).

\section{Consumption}

Research on media content however cannot be matched in number and quality by studies on the consumption of media content and the public's perception of the environment. Research examining the public's perception of media content or of environmental risks is scarce Among the few studies on related topics, apart from the study by Zeng and his collaborators discussed above (Zeng, et al., 2015), the study by Qiu is important (Qiu, 2014). A survey of 200 villagers living close to the Ningde Nuclear Plant, it discloses how the demographics of residents, especially education, influenced their perception of nuclear risks and their acceptance of having a nuclear plant in their backyard. In another study, Qiu and Wu collected survey data from 225 residents in an area with extensive water pollution (Qiu \& Wu, 2013). They managed to show the impact of internet usage on public trust in local governments. Their findings also indicate a big digital divide between urban and rural residents on this matter. Nevertheless, the two studies were conducted for the benefit of governments, as their aim was to provide consultancy on how governments should manage risk communication and how to effectively communicate with residents in order to persuade them. This echoes the progovernment stance of scholars who study the production side of environmental communication. 


\section{Missing dimensions, challenges and several future directions}

The discussion in the previous sections has outlined three main missing dimensions in the current Chinese-language literature in this burgeoning field. Firstly, there is a severe lack of research examining power struggles in news production processes that might shape news output. Most research has a focus on news content, paying scant attention to the production side of environmental communication. Current literature has examined the communication strategies and practices of environmental pressure and protest groups and social movements. However, important issues such as the media strategies and practices of big businesses, large corporations, governments and officials and the relationship between news media and their news sources remain unknown. To understand why news coverage is the way it is, requires us to obtain sound knowledge of what has happened in the news production process. Powers compete to shape and control the discourse of the environment, which is conventionally regarded as being socially, politically and culturally constructed. It is important to look into the practices of powers at both institutional and individual levels and the associated influencing factors that shape news output. Such practices and influencing factors not merely refer to the media management skills of governments, big businesses, corporations and other powerful social entities and individuals such as scientists, as argued by Hansen (2011 and 2015), but also mean the practices, ideals and epistemology of environmental journalists (Tong, 2015a; Tong, 2015b) and the principles and values of news organisations. Establishing knowledge about these aspects can explain why news media represent the environment in particular ways and why they give more prominence to certain environmental problems than to others; a more thorough picture of which also needs to be arrived at by an all-round and longitudinal analysis of news content.

Secondly, although there are quite a number of studies examining media representation of environmental events, little knowledge is available on the image and discourse of nature and the environment, and not much research has been done on the subject of the representation of environmental problems in media texts and images. If we want to understand environmental 
communication and how it works in China we must understand what news media say about the environment and environmental problems, given the mediation role of the media. This is in part because news coverage of the environment and green issues is the site where the public receives information about them which might influence their perceptions of these issues. One vital way to understand the nature of mediated environmental communication is through the analysis of media content. This is also because the way in which the environment and environmental problems are represented can reveal prevailing environmentalism, the relationship between humanity and nature, as well as diverse and even competing interests and ideologies in a society, from which we can better understand social dynamics in the wider context. In addition, when we adopt Western social theories, our studies might be able to benefit more if we can critically examine such theories and consider their applicability in the context of China.

The third missing dimension is about how the public perceive environmental problems and consume media representations of the environment and environmental problems. Without knowledge about this, we can only have a patchy understanding of environmental communication in China. The public's perception of the prevalence of environmental problems plays an important role in policy-making. In addition, while recognising the agenda-setting function and effects of news media, we cannot ignore the active role played by the public in consuming media products. How the public perceive certain environmental issues and problems in reality and in media coverage impacts on public opinions about them and therefore might influence policy-making on related issues. Clearly the current gap in research in this domain prevents us from comprehending how the environment and related issues are conceived, how news media and audiences interact, and how the general public take part in environmental communication, a consequence of which is our lack of the knowledge about how environmental communication is changing our lives.

Associated with these missing dimensions are three challenges: political stances, methodological, and analytical challenges. Reviewing English-language literature on environmental communication, 
Lester contended that it is extremely important to reflect on how environmental communication researchers can maintain their critical stance while attempting to gain funding support from governments and even large corporations and industry (Lester, 2015). Likewise, for Chineselanguage studies on environmental communication, one of the most pressing challenges is whether and how scholars can take a critical stance toward the issues studied. Issues surrounding the environment may be connected with social conflicts such as the tension embodied in the rivalry between the environment and modernisation (Tong, 2015c). Therefore, studies of related topics may touch the nerve of the ruling authorities. Given the social, political and cultural conditions in authoritarian China, adopting a critical stance may not be realistic for intellectuals, especially for researchers who receive funding from the government or commercial bodies or who work in conservative Chinese universities and disciplines (Hao, 2003: 101 and 242). Seeing environmental reporting as an extension of party work or party reporting cannot meet the aim to take a critical stance at all. This, however, makes scholars' maintaining a critical stance extremely important so as to exert influence over society and to retain academic independence and liberty.

The second challenge is methodological, in relation to adopting diverse approaches to research objects, employing empirical research methods and collecting empirical data. The need is urgent to distinguish between empirical and primary research articles and theoretical discussion articles. For the former, transparent research design and processes as well as systematic and rigorous data collection should be used and discussed in detail, while logic and induction should be at the centre of the latter, with particular and close attention given to how to contribute to theories, most of which have so far been developed in the Western context. Chinese-language environmental communication research would be more plural, if the dominance of content analysis can be reduced and provided that scholars can employ empirical research methods such as interviews, focus groups, observations and surveys to collect data from human subjects. Collecting data from human subjects such as government officials, business people, journalists and the general public requires financial support as well as the collaboration of these target interviewees, which creates difficulties for 
research of this kind. The fact that the closer and more oppressive the society is, the less likely target interviewees are to accept might also be responsible for the lack of academic application of such research methods (Zhou \& Nunes, 2013). Apart from that, difficulties can also come from the fact that such studies require researchers to be equipped with all-round knowledge of research methodologies, skills in research design and the capability of carrying out research.

When thinking of content analysis, not only word-based media texts but also visual forms of media texts such as photos and cartoons also deserve our scholarly attention. In addition, as Hansen argues, a systematic and longitudinal analysis of media content is necessary, as this can tell us the long-term trend of particular environmental discourses and images. The prerequisite for conducting such an analysis however is the establishment and availability of complete and user-friendly databases that comprise systematic records of all media publications over many years. There are a number of databases available such as the China Important Newspapers Database (zhongguo zhongyao baozhi shujuku), the Digital Newspapers Repository and the Hongkong-based Wisers database. These databases normally require subscriptions, which are not cheap. This means some less well-off universities and academic institutions may be unable to afford them, let alone independent researchers. The thought that some scholars can access these databases but others cannot might be uncomfortable. In addition, these databases comprise an incomplete collection of newspapers. For example, the China Important Newspapers Database only includes those that are regarded as important newspapers and excludes some, such as the Southern Metropolitan Daily and the Beijing Youth although they are socially and politically influential. Therefore, even for those researchers who have access to these databases, none of them has a collection of news media content available to establish a complete and longitudinal picture of media representation. The analysis of visual forms of news content is even more difficult, due to the fact that researchers may have to manually collect the samples for their analysis. 
Anderson identifies several trends in environmental communication research such as the 'mediacentric approach' and the 'information deficit model' and regards it necessary to embrace the opportunities and tackle the challenges brought up by the 'new media landscape' through an interdisciplinary effort (Anderson, 2015). This need, however, is even more difficult to fulfil in the context of China. Apart from what was discussed above, the main obstacle to the analysis of social media content in order to understand online discourses of the environment and environmental problems is associated with the computational and data analytics skills needed for large-scale data analysis and social media data analysis. This challenge - not unique to China - results from the fact that large-scale data analysis and social media analysis requires inter-disciplinary collaboration and innovative research methodologies and methods, with which most social science researchers are unfamiliar (not to mention the reality where big tech firms such as Baidu and Sina monopolise the data needed for research).

The third challenge lies at the analytical level. What should be the focus of analysis - structure or agents? Environmental communication research is more likely to focus on the performance of agents such as actors ranging from environmental protestors, campaigners, to journalists rather than on structure. Such an analysis of agency however may lead to ignoring the overall picture of the structural transformation of environmental communication as well as the influences of social and cultural contexts on environmental communication. Just as Cox, who proposes considering the complexity at the structural level and advances to analyse communicative and media systems (Cox, 2015), it is important to analyse how the structure of Chinese society and the structural changes in Chinese society shape environmental communication and therefore our lives. Having this said though, we stress the value of both analysing the actual practices of agents and considering the influence of social structures such as national politics, ideologies, systems of cultural values, modernisation and even China's position in the global economy and geopolitics. 
To conclude, while we have seen recent encouraging progress in Chinese-language literature on China's environmental communication, we indeed need more to be done to examine the complicated dynamics and their influence on the news production process, media discourses and representations of the environment, environmental problems and nature, as well as the public perception and media representation of the environment. A great amount of effort is required from individual scholars and scholarly communities and institutions to tackle the three challenges outlined above - the question of critical stance, methodological and analytical issues in order to help further to develop research about environmental communication in and about China. 


\section{Acknowledgement}

The author is grateful to Professor Francis Lee for his invitation to write this article and for his patience. Thanks also go to the anonymous reviewers for their valuable comments. 


\section{Bibliography:}

Alexander, J. (2013). The case of the green vampire: eco-celebrity, Twitter and youth engagement. Celebrity Studies, 4(3), 353-368.

Anderson, A. (2015). Reflections on Environmental Communication and the Challenges of a New Research Agenda. Environmental Communication, 9(3), 379-383.

Autry, M. K., \& Kell, A. R. (2012). Merging Duke Energy and Progress Energy: Online Public Discourse, Post-Fukushima Reactions, and the Absence of Environmental Communication. nvironmental Communication, 6(2), 278-284.

Bai, H. (2014). The News Paradigms in the Coverage of Environmental Protests- a case study of three NIMBY (not-in-my-backyard) conflicts (huanjing kangzhen baodao de xinwen fanshi yanjiu yi sanqi lingbi chongtu shijian weili). Modern Communication (xiandai chuanbo), 1, 45-50.

Beck, U. (1992). Risk Society: Towards a New Modernity. London, New Delhi, Thousand Oaks: SAGE Publications.

Bødker, H., \& Neverla, I. (2012). Introduction: Environmental Jouranlism. Journalism Studies, 13(2), 152-156.

Bortree, D. S. (2012). Pro-environmental behaviours through social media: an analysis of Twitter communication strategies. In L. Ahern \& D. S. Bortree (Eds.), Talking green: exploring contemporary issues in environmental communication. New York: Peter Lang.

Chen, C. (2012). Hot and New Topics of Environmental News (huanjing xinwen de redian ji baodao xin silu). Young Journalists (qingnian jizhe), 29, 37-38.

Cox, R. (2013). Environmental Communication and the Public Sphere. Los Angeles, London, New Delhi, Singapore, and Washington DC: SAGE.

Cox, R. (2015). Scale, Complexity, and Communicative Systems. Environmental Communication, 9(3), 370-378.

Cox, R., \& Depoe, S. (2015). Emergence and growth of the "field" of environmental communication. In A. Hansen \& R. Cox (Eds.), The Routledge Handbook of Environment and Communication. London: Routledge.

Fong, M. (2008). Beijing limits protests, media access in quake zone; rally on deaths of children halted; a 'matter of time.'. The Wall Street Journal Eastern Edition, 0, A14(11).

Hansen, A. (2011). Communication, media and environment: Towards reconnecting research on the production, content and social implications of environmental communication. International Communication Gazette, 73(1-2), 7-25.

Hansen, A. (2015). Promising Directions for Environmental Communication Research. Environmental Communication, 9(3), 384-391.

Hansen, A., \& Cox, R. (2015a). Introduction: environment and communication. In A. Hansen \& R. Cox (Eds.), The Routledge Handbook of Environment and Communication (pp. 1-10). London: Routledge.

Hansen, A., \& Cox, R. (Eds.). (2015b). The Routledge Handbook of Environment and Communication. London: Routledge.

Hao, Z. (2003). Intellectuals at a Crossroads : The Changing Politics of China's Knowledge Workers. Albany: State University of New York Press.

Huang, B., \& Lei, H. (2013). The Inbalance between Functions of Propaganda and Monitoring the Environment: Reflections over Paradigm-Reporting in Chutian Metropolitan Daily (xuanchuan gongneng yu jianshi huanjing gongneng de shiheng zhuliuhua zhuanxing xia chutian dushibao dianxing baodao fansi). News Knowledge (xinwen zhishi), 2, 27-28.

Huang, H., \& Liu, L. (2014). The Construction of Environmental Agenda in Mainstream News Media: a case study of environmental reports by the People's Daily from 2003-2012 (lun chuantong zhuliu meiti dui huanjing yiti de jiangou yi renmin ribao 2003 zhi 2012 nian de huanjing baodao weili). Journalism and Communication Study (xinwen yu chuanbo yanjiu), 10, 53-65. 
Huang, W., \& Ding, N. (2010). Sino-US Mainstream Media Divergence in National Interests Notion:The Cases of News Coverage during Copenhagen Climate Summit on Guangming Daily and New York Times (shixi zhongmei zhuliu meiti de guojia liyi guan chayi yi niuyueshibao he guangmin ribao de geben hagen qihou fenghui baodao gexing wei anli yanjiu). Journalism and Communication Study (xinwen yu chuanbo yanjiu), 5, 55-63.

Huang, Y., \& Zeng, F. (2010). From "Not In My Back Yard" to Policy Advocacy: The Co-empowerment Model between Media and Protests in China Mass Communication Research (xinwenxue yanjiu), 109, 167-200.

Ji, M. (2007). About the Three Phases in the Development of Environmental News in China (lun woguo huanjing xinwen fazhan de sange jieduan). Shuzhou University, Shuzhou.

Katz-Kimchi, M., \& Goodwin, B. (2015). Forum:Organizing and Integrating Knowledge about Environmental Communication. Environmental Communication, 9(3), 367-369.

Lester, L. (2015). Three Challenges for Environmental Communication Research. Environmental Communication, 9(3), 392-397.

Li, Q., \& He, D. (2000). About Several Key Points of How to Properly Conduct Environmental Reporting Propaganda Work (lun zuohao huanjing xinwen xuanchuan baodao gongzuo de jige yaodian). North Environment (beifang huanjing), 3.

Li, R. (2007a). The Development of Environmental News and Reporting Patterns (huanjing xinwen de zoushi ji baodao lujing). China Journalists (zhongguo jizhe), 7(16), 34-35.

Li, W. (2007b). About Propaganda Strategies of News Media Reporting on Environmental Problems (lun xinwen meiti dui huanjing wenti de xuanchuan celue). News Communication (xinwen chuanbo), 10, 58-60.

Li, W., Yang, C., \& Yang, M. (2015). Risk Communication on Water Resources- a content anaysis of news coverage of the 2014 Three Gorges Project Event (fengxian goutong shiye zhong shuiziyuan yiti de chuanbo changyu moshi yu youhua lujing jiyu 2014 nian sanxia gongcheng tiaodu fengxian shijian de wenben fenxi). Modern Communication (xiandai chuanbo), 6, 5660.

Liang, Y., \& Deng, S. (2006). The Sustainable Perspective in Environmental Reporting (huanjing baodao zhongde kechixu fazhan shijiao). China Journalists (zhongguo jizhe), 4, 72-73.

Liu, K. (2010). The Image of China in British Print Press: a case study of climate change related reports. Modern Communication (xiandai chuanbo), 170(9), 57-60.

Liu, T. (2014). The Symbolic Reconstruction and Rhetoric Practices in Reporting on Environmenal Public Events: a case study of the symbolic analysis of Lanzhou Tap Water Pollution Event (huanjing gonggong shijian de fuhao zaizao yu xiuchi shijian jiyu lanzhou zilaishui wuran shijian de fuhaoxue fenxi). Journalism Bimonthly (xinwen daxue), 128(6), 24-31.

Merry, M. K. (2014). Broadcast Versus Interaction: Environmental Groups' Use of Twitter. Journal of Information Technology \& Politics, 11(3), 329-344.

Pei, S. (2009). Influencing factors in Environmental News Production Process: a case study (woguo huanjing xinwen shengchan yingxiang yinsu de gean fenxi). ,MA, Xiamen University, Xiamen.

Qiu, H. (2014). New Class, Nuclear Risk and Environmental Communication: Social foundation for Environmental Attention and Government's Response in the Case of Ningde Nuclear Plant (xin jieji he fengxian yu huanjing chuanbo ningde hedianzhan huanjing guanzhu de shehui jichu ji zhengfu yingdui). Modern Communication (xiandai chuanbo), 10, 26-32.

Qiu, H., \& Wu, S. (2013). Internet Use, Public Trust, and Risk Communication in a Water Pollution Area (wangluo shiyong gongzhong xinren yu shui wuran fengxian chuanbo). Chinese Journal of Journalism \& Communication, 10, 117-130.

Qu, R., \& Lu, T. (2010). A Comparative Analysis of the Coverage of Copenhagen Climate Change Summit in the People's Daily and the Los Angeles Times (renmin ribao luoshanji shibao guanyu gebenhagen qihou dahui baodao de duibi yanjiu). Modern Communication (xiandai chuanbo), 171(10), 144-145. 
Shi, X., Zi, Z., Feng, J., \& Fan, F. (2010). Research on the Content of Environmental News in China: a case study of the People's Daily (huanjing xinwen baodao de neirong ji shikong guilv yanjiu yi renmin ribao weili). Journal of Jiangxi Normal University (jiangxi shifan daxue xuebao), 4, 2229.

Sun, W. (2009). An Analysis of the Functions of Environmental Reports in Transitional China- Social Movements in 'New Social Movements' (zhuanxing zhongguo huanjingbao de gongneng fenxi xin shehui yundong zhong de shehui yundong). International Journalism (Guoji Xinwenjie), 1, 118-122.

Tian, Y. (2009). Changes in Idea: from 'Conquering Nature' to 'Being Close to Nature' and Discussing Ecology Aesthetics in Documentaries (linian de zhuanbian cong zhengfu ziran dao qinjin ziran jiantan jilupian zhong de shengtai meixue). Modern Communication (xiandai chuanbo), 158(3), 88-90.

Tilt, B., \& Xiao, Q. (2010). Media coverage of environmental pollution in the People's Republic of China: responsibility, cover-up and state control. Media, Culture \& Society, 32(2), 225-245.

Tong, J. (2015a). Being Objective With a Personal Perspective How Environmental Journalists at Two Chinese Newspapers Articulate and Practice Objectivity. Science Communication, 37(6), 747768.

Tong, J. (2015b). The Epistemology of Environmental Journalists: the case of China. Journalism Studies, Online First.

Tong, J. (2015c). Investigative Journalism, Environmental Problems and Modernisation in China. London: Palgrave Macmillan.

Tong, J., \& Sparks, C. (2009). Investigative Journalism in China Today. Journalism Studies, 10(3).

Wang, H., \& Lee, F. L. F. (2014). Research on Chinese Investigative Journalism, 1978-2013: A Critical Review. China Review, Fall, 215-251.

Wang, L. (2005). Green Media: Environmental Communicaiton in China (Ivmeiti zhongguo huanbao chuanbo yanjiu). Beijing: Qinghua University Press.

Wang, Q. (2014). The Media's Responsibility Strategies and Haze Risk: a content analysis of coverage of haze on the People.net (meiti guiyin guize celue yu bei wuhua de wumai fengxian jiyu dui renminwang wumai baodao de neirong fenxi). Modern Communication (xiandai chuanbo), 221(12), 37-42.

Xu, Q., \& Yu, Y. (2010). An Analysis of How French Media Report on China: a case study of the coverage of haze in French newspapers (faguo meiti duihua baodao jiexi yi faguo baokan guanyu wumai baodao weili). Modern Communication (xiandai chuanbo), 207(10), 140-141.

Yin, Y. (2010). The Display and Concealment of Risk: the Media Construction of Environmenatl Risk in the coverage of Taihu Lake Pollution (fenxian de chenxian jiqi yingni cong taihushui wuran baodao kan huanjing fenxian de meiti jiangou). International Journalism (Guoji Xinwenjie), 11, 50-55.

Zeng, F. (2009a). The Construction of NGO agenda under the Control of the State: the Case of China (guojia kongzhi xiade ngo yiti jiangou yi zhongguo yiti weili). Communication and Society (chuanbo yu shehui), 8, 19-53.

Zeng, F. (2009b). The Role of News Media in Contemporary Environmental Movements in China: from China's Environmental Protection New Century Tour to the Xiamen PX Protest (dangdai zhongguo huanjing yundong zhong de meiti juese cong zhonghua huanbao shijixing dao xiamen PX). Morden Adversiting (xiandai guanggao), 171, 36-41.

Zeng, F., Dai, J., \& Wang, Y. (2015). Technological Risk VS Perception of Risk: Communication Process and Social Amplification of Risk (jishu fengxian vs ganzhi fengxian chuanbo guocheng yu fengxian shehui fangda). Modern Communication (xiandai chuanbo), 224(3), 40-46.

Zeng, F., Dai, J., \& Zheng, J. (2013). Frames Contest, Resonation and Diffusion: An Analysis on News Coverage of PM2.5 Issue (kuangjia zhengduo gongming yu kuosan $p, 2,5$ yiti de meijie baodao fenxi). Chinese Journal of Journalism \& Communication (guoji xinwen jie), 35(8), 96-108. 
Zhang, W. (2007). Propaganda Function of Environmental Reporting and Objectivity in News (huanijng baodao de xuanchuan secai yu xinwen de keguanxin). International Journalism (Guoji Xinwenjie), 10, 19-23.

Zhao, S., \& Zhou, Z. (2012). The Changes in the Concepts of Reports on Emergency Environmental Events in China in the 21st Century (ershiyi shiji zhongguo tufa huanjing shijian baodao de guannian biange). Journalists (xinwen jizhe), 2.

Zhou, L., \& Nunes, M. B. (2013). Doing qualitative research in Chinese contexts; Lessons learned from conducting interviews in a Chinese healthcare environment. Library Hi Tech, 31(3), 419434. 
Figures and table:

Figure 1 Distribution of publications over time

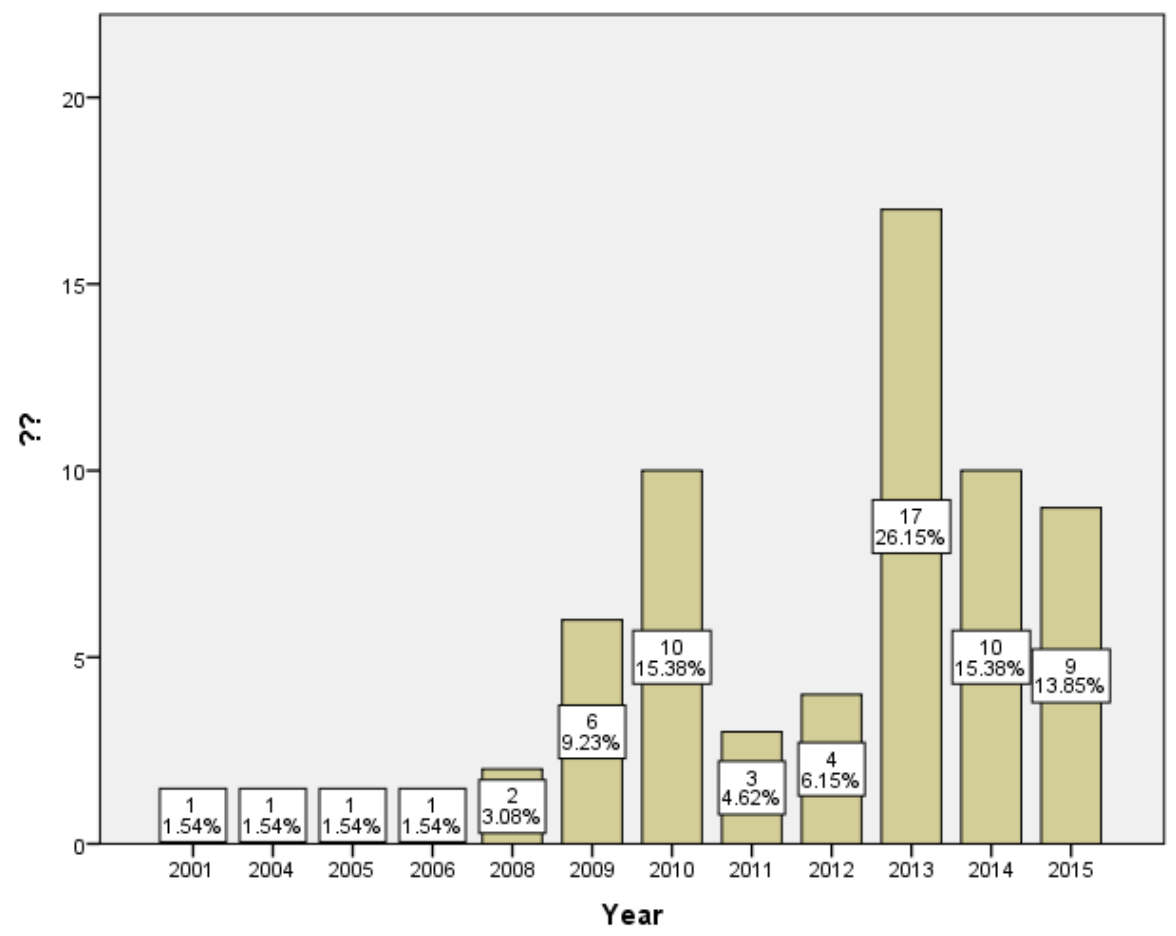

Figure 2 Number of publications per journal

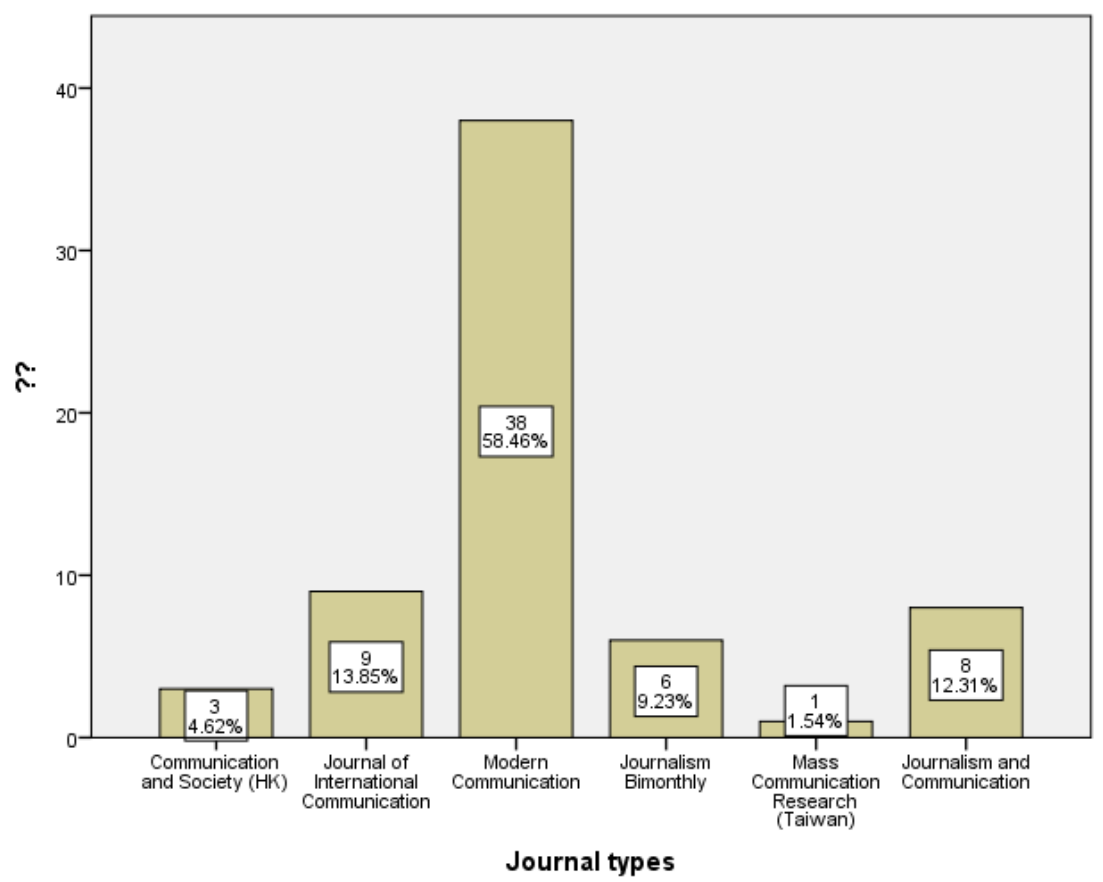


Figure 3 Citation of English-language literature

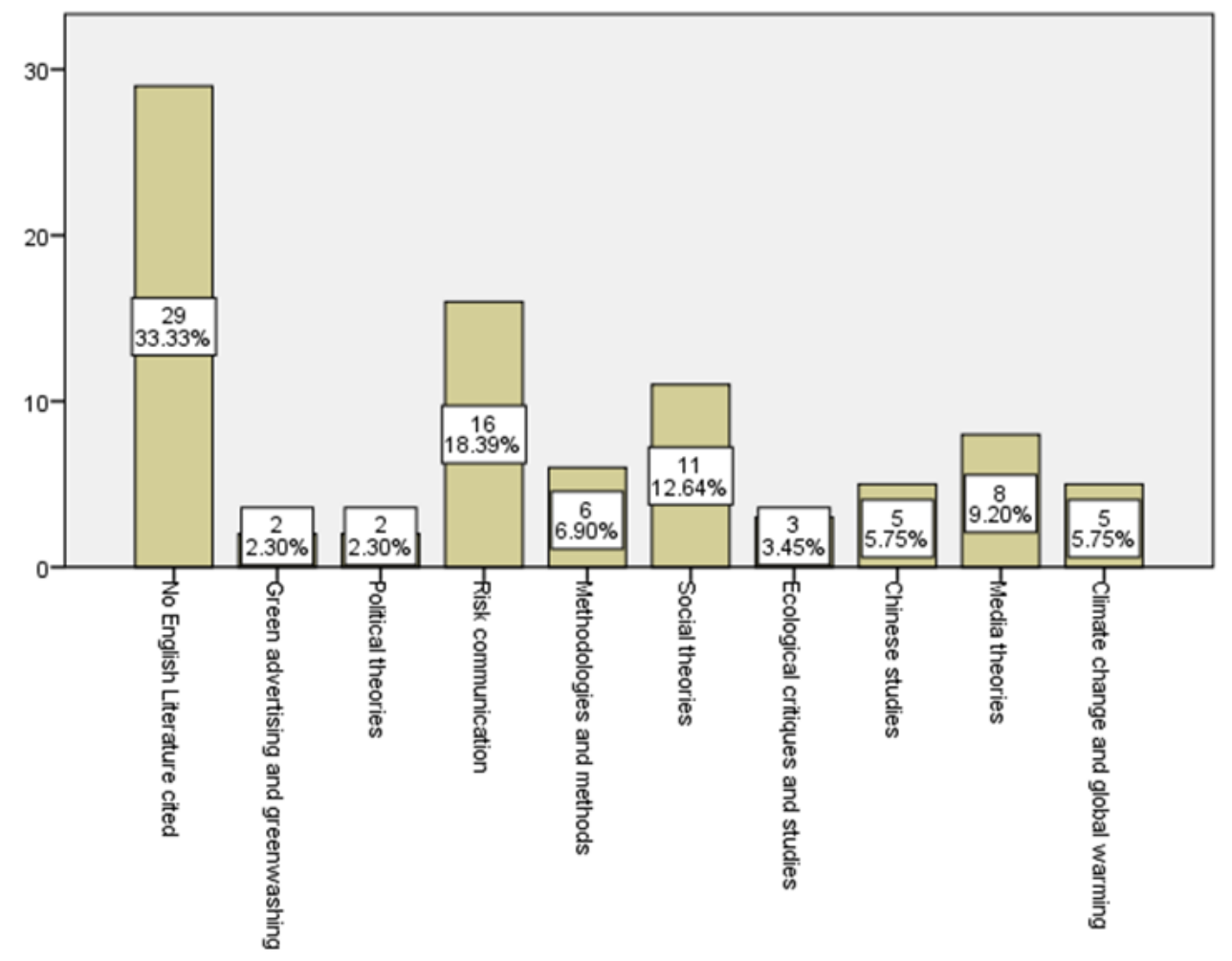


Figure 4 Citation of English-language literature over time

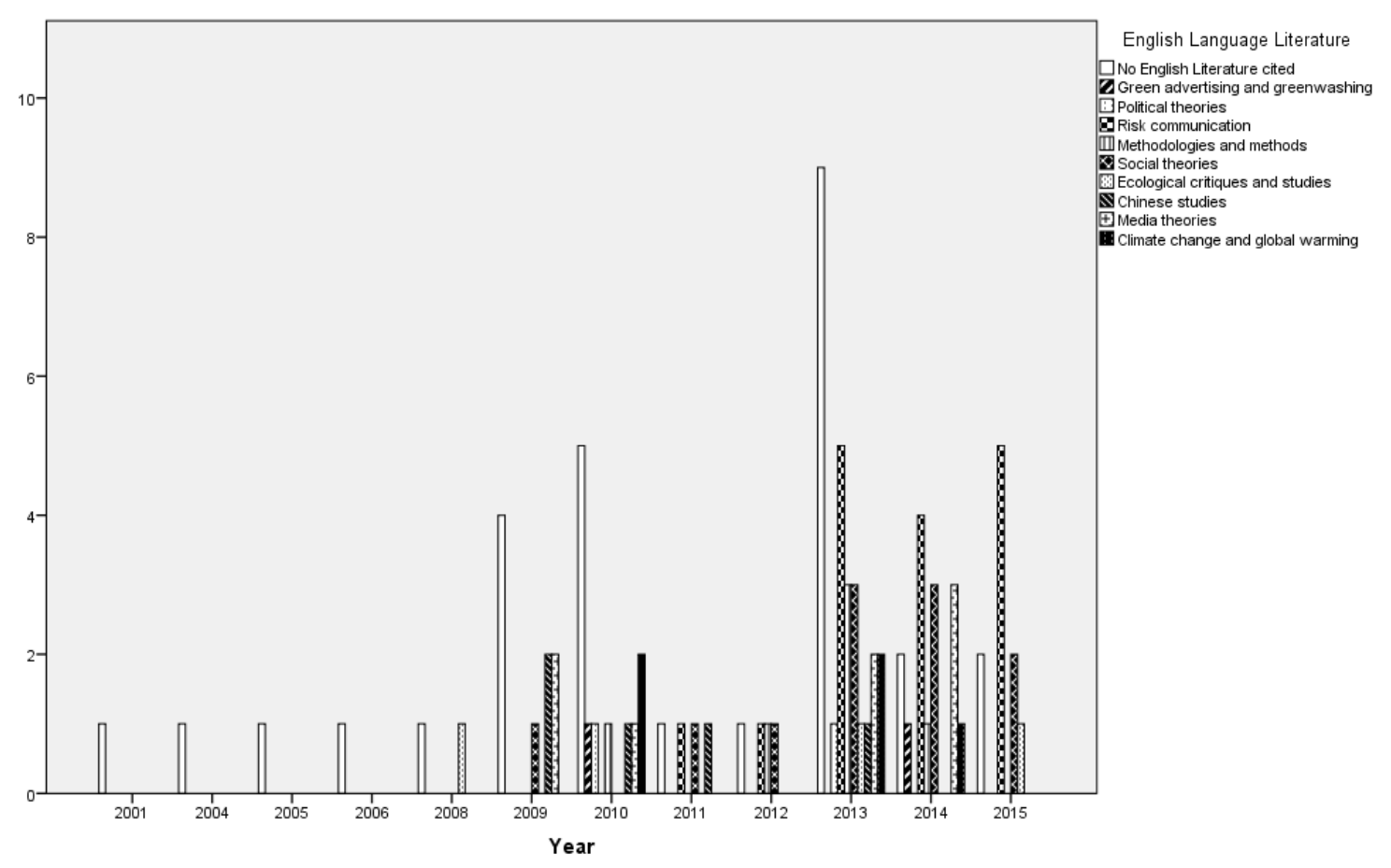




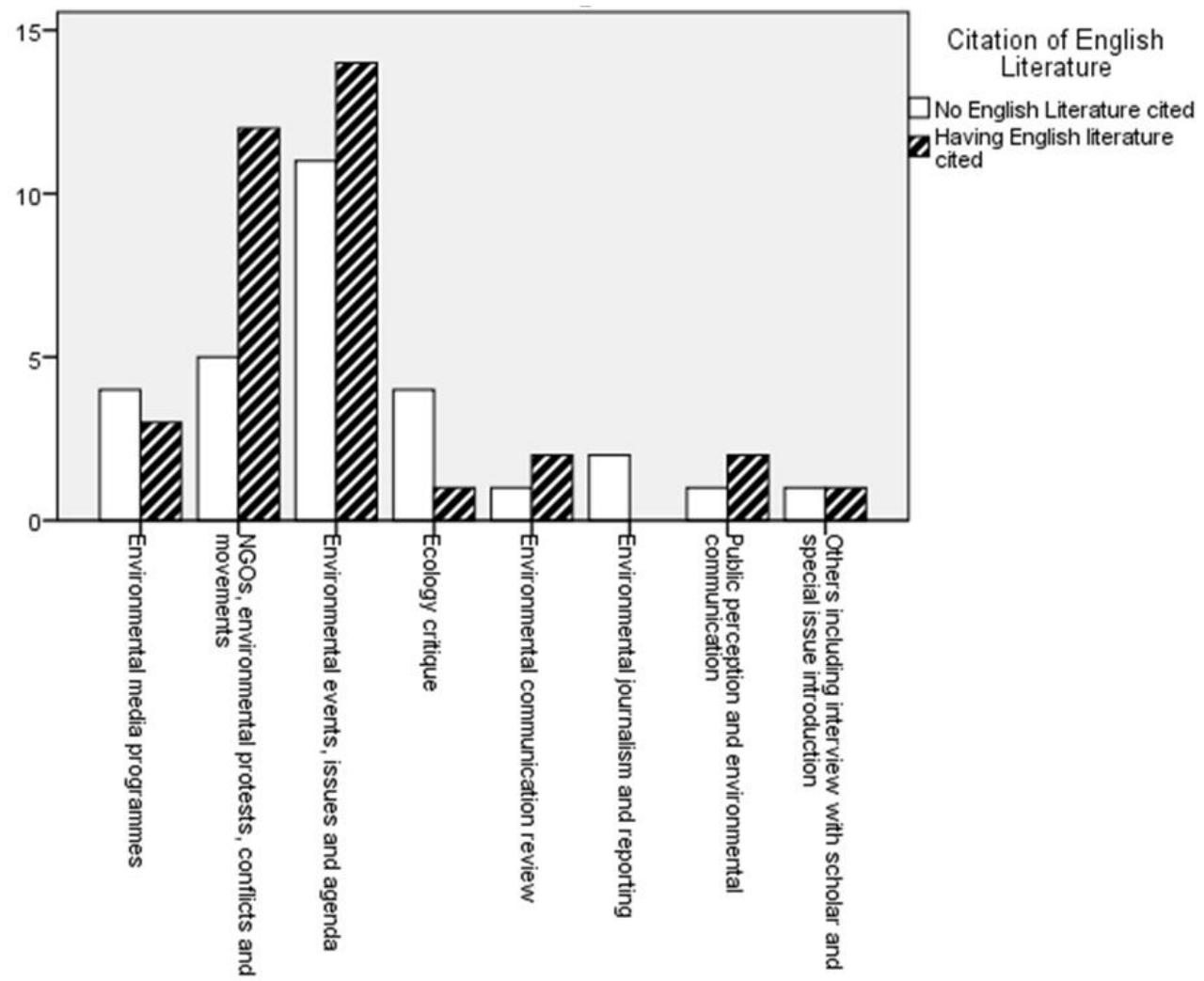

Table 1 Topic types

\begin{tabular}{|l|l|}
\hline Topic Type & Number (Percentage) \\
\hline Environmental events, issues and agenda & $25(39.1)$ \\
\hline NGOs, environment protests, conflicts and movement & $17(26.6)$ \\
\hline Environmental media programmes & $7(10.8)$ \\
\hline Ecology critique & $5(7.8)$ \\
\hline Public perception and environmental communication & $3(4.7)$ \\
\hline Environmental communication review & $3(4.7)$ \\
\hline Others including interview with scholar and special issue introduction & $2(3.1)$ \\
\hline Environmental journalism and reporting & $2(3.1)$ \\
\hline
\end{tabular}




\footnotetext{
${ }^{1}$ In the tests, different keywords were used in the search. Apart from the above nine keywords eventually used in the research, keywords such as 'pollution' (wuran), 'radiation' (fushe) and 'water contamination' (shui wuran) were used too. However, the results coming back from the search by using the nine keywords had already included those generated by using other keywords that therefore were removed.

${ }^{2}$ The selection of the three academic disciplines excludes the articles published by journals in other disciplines such as Accounting Research (kuaiji yanjiu) and China Population Resources and Environment (zhongguo renkou ziyuan yu huanjing) in the analysis.

${ }^{3}$ Asia Pulp \& Paper (APP), based in Indonesia, is a large pulp and papermaking company.
} 